\title{
Nontumorous Portal Vein Thrombosis in Liver Cirrhosis: Possible Role of $\beta$-Blockers
}

\author{
Lydia Giannitrapani $^{a}$ Walter Granà ${ }^{a}$ Anna Licata $^{a}$ Cosima Schiavone $^{b}$ \\ Giuseppe Montalto $^{a}$ Maurizio Soresi ${ }^{a}$
}

a Biomedical Department of Internal Medicine and Specialties, Faculty of Medicine, Palermo University,

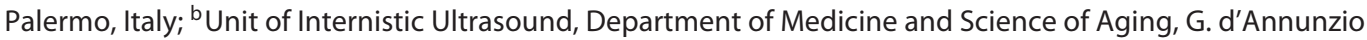
University, Chieti, Italy

\section{Significance of the Study}

- Novel risk factors of portal vein thrombosis in patients with liver cirrhosis include the use of nonselective $\beta$-blockers. We found that the use of nonselective $\beta$-blockers indicated a higher risk of portal vein thrombosis compared to selective $\beta$-blockers. Our data seem to support the thesis that portal vein thrombosis development could be favored by reduction of the portal flow.

\section{Keywords}

Bleeding prevention therapy - Cirrhosis complications . Nonselective $\beta$-blockers · Risk of thrombosis

\begin{abstract}
Objective: Nonselective $\beta$-blockers (NSBB) are used in liver cirrhosis (LC) to prevent variceal bleeding because they decrease portal pressure. A main risk factor for the development of portal vein thrombosis (PVT) in LC is decreased portal vein inflow velocity. The aim of our study was to examine retrospectively the incidence of PVT and its correlation with the use of $\beta$-blockers in a cohort of LC patients. Subjects and Methods: Data from 230 LC patients (90\% Child-Pugh class A), who had been followed up for at least 5 years, were reviewed. The diagnosis of PVT was made by ultrasound. The
\end{abstract}

\begin{tabular}{ll}
\hline KARGER & $\begin{array}{l}\text { ( } 2018 \text { The Author(s) Karger } \\
\text { Published by S. Karger AG, Basel Open caccess }\end{array}$ \\
E-Mail karger@karger.com & $\begin{array}{l}\text { This is an Open Access article licensed under the Creative Commons } \\
\text { Attribution-NonCommercial-4.0 International License (CC BY-NC) } \\
\text { (http://www.karger.com/Services/OpenAccessLicense), applicable to } \\
\text { the online version of the article only. Usage and distribution for } \\
\text { commercial purposes requires written permission. }\end{array}$
\end{tabular}

presence of PVT was evaluated with multiple logistic regression analysis where the independent variables were those significant in the univariate analysis. Results: The prevalence of PVT at baseline was $4.5 \%$, and the incidence was $4.3 \%$ at 5 years; among the subjects taking $\beta$ blockers, $46.4 \%$ were taking NSBB. A total of 19 PVT cases were found. Grade of esophageal varices $(p<0.01)$, PLT $(p<0.003)$, INR $(p<0.03)$, spleen diameter $(p<0.001)$ and PLT/spleen ratio $(p<0.0005)$ were significantly associated with PVT. The use of NSBB indicated a higher risk of PVT compared to selective $\beta$-blockers (SBB) $(p<0.05)$. In logistic regression analysis only the grade of esophageal varices was significant $(p<0.02)$. Univariate analysis of patients taking $\beta$-blockers showed an association of PVT with grade of esophageal varices $(p<0.01)$, CP class $(p<0.02)$, AST $(p<0.03)$, ALT and albumin $(p<0.02)$, PLT count and PLT/LD $(p<0.03)$, longitudinal diameter of the
Lydia Giannitrapani

Biomedical Department of Internal Medicine and Specialties, University of Palermo via del Vespro 141

IT-90127 Palermo (Italy)

E-Mail lydia.giannitrapani@unipa.it 
spleen $(p<0.005)$, ascites $(p<0.05)$, portal vein $(p<0.0001)$ and NSBB (OR 8.1; $95 \% \mathrm{Cl}$ 1.7-38.8). Conclusion: NSBB seem to play a role in PV thrombogenesis. Further studies are needed, especially in decompensated LC patients.

(C) 2018 The Author(s)

Published by S. Karger AG, Basel

\section{Introduction}

Acute PVT was recently defined in the Clinical Practice Guidelines of the European Association for the Study of the Liver as a recent formation of a thrombus within the portal vein and/or within its right or left branches [1]. When an obstruction of the portal vein is present in addition to PVT, other causes must be taken into account, including obstructions associated with cancer; tumors can lead to portal occlusion by invasion (frequently found in hepatocellular carcinoma) or by compression (most frequently linked to pancreatic tumors or cholangiocarcinoma). Most PVT cases, however, occur in the cirrhotic liver, especially in decompensated cirrhosis, while cases of PVT in the healthy liver are rare, at least in developed countries. The causes underlying PVT are the same as those of thrombotic processes in general, i.e. slowdown of the blood flow, hypercoagulation and endothelial damage. In cirrhotic subjects various prothrombotic conditions coexist, especially coagulation alterations, while according to recent studies $[2,3]$ the most important of all is slowdown of the portal circulation.

Nonselective $\beta$-blockers (NSBB) are the treatment of choice for primary and secondary prevention of variceal bleeding; the action of NSBB leads to a reduction in portal flow velocity and, as a result, in portal pressure [4-6]. Consequently, if portal flow alteration is indeed the main determining factor in the genesis of PVT in cirrhosis, it is reasonable to think that these drugs, with further reduction of the portal flow, can increase the risk of PVT. Some authors have recently suggested a possible predisposing role for NSBB in the onset of PVT in liver cirrhosis (LC) patients $[7,8]$. The aim of our study was therefore to investigate the onset of PVT and its possible correlation with $\beta$-blocker therapy through a retrospective evaluation of cirrhotic patients referred to our clinic.

\section{Subjects and Methods}

Patients

The medical records of 420 cirrhotic patients followed as outpatients at our Internal Medicine Unit were retrospectively ana-
Fig. 1. Breakdown of the study population based on inclusion and exclusion criteria.

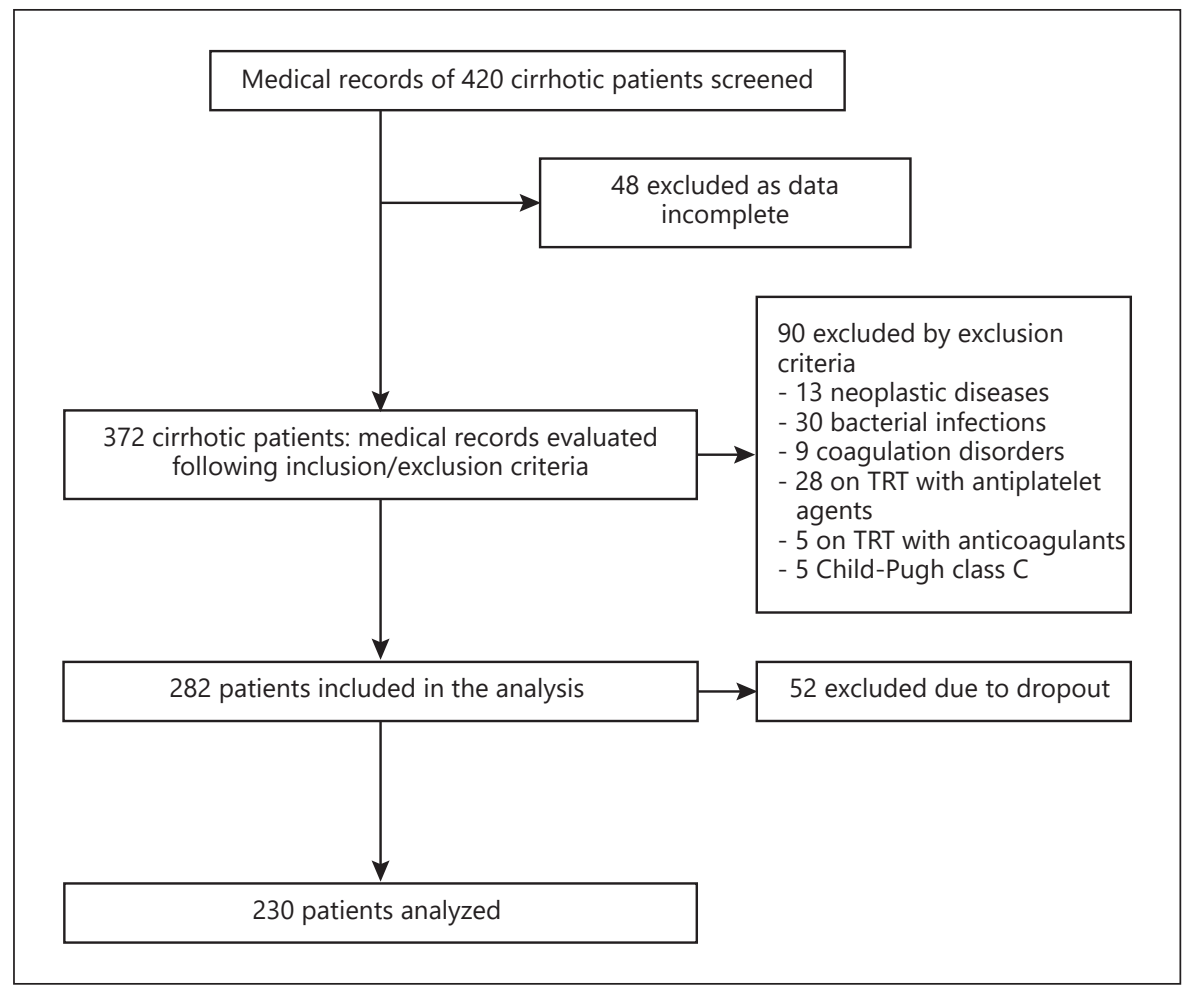


Table 1. Baseline clinical, biochemical, and demographic features of the enrolled patients

\begin{tabular}{|c|c|}
\hline Main characteristics (normal values) & $\begin{array}{l}\text { Patients } \\
(n=230)\end{array}$ \\
\hline Age, years & $62.5 \pm 10.8$ \\
\hline Males, $n$ & 140 \\
\hline Females, $n$ & 90 \\
\hline \multicolumn{2}{|l|}{ LC etiology } \\
\hline $\mathrm{HCV}$ & $168(73)$ \\
\hline $\mathrm{HBV}$ & $12(5.1)$ \\
\hline Alcoholic & $7(3.0)$ \\
\hline Metabolic & $5(2.2)$ \\
\hline Autoimmune & $4(1.7)$ \\
\hline Cryptogenic & $18(7.8)$ \\
\hline Other & $16(6.9)$ \\
\hline \multicolumn{2}{|l|}{ Child-Pugh class } \\
\hline A & $203(88.2)$ \\
\hline B & $27(11.8)$ \\
\hline Bilirubin $^{\mathrm{a}}, \mathrm{g} / \mathrm{dL}$ & $0.9 \pm 0.5$ \\
\hline Albumin ${ }^{\mathrm{b}}, \mathrm{g} / \mathrm{L}$ & $3.9 \pm 0.5$ \\
\hline $\mathrm{PLT}$ count $^{\mathrm{c}}, n \times 10^{3} / \mathrm{L}$ & $123(8.6-387)$ \\
\hline INR & $1.1 \pm 0.2$ \\
\hline
\end{tabular}

Values are presented as means $\pm \mathrm{SD}$, medians (range), or numbers (\%) unless otherwise stated. ${ }^{a}$ Normal range: $0.3-1.2 \mathrm{~g} / \mathrm{dL}$. ${ }^{\mathrm{b}}$ Normal range: $3.4-4.8 \mathrm{~g} / \mathrm{L} .{ }^{\mathrm{c}}$ Normal range: $140-450 \times 10^{3} / \mathrm{L}$. d Normal range: $0.8-1.2$.

lyzed. All of the patients had been diagnosed by liver biopsy or unequivocal clinical, blood chemistry and instrumental data.

Exclusion criteria included the presence of neoplastic diseases, bacterial infections or coagulation disorders, current treatment with anticoagulants, antiplatelet agents and oral contraceptives and antiviral or immunomodulatory therapies in the previous 6 months. A further selection excluded patients with incomplete data, as well as Child-Pugh class C subjects, due to their small number in the study population. The cohort was thus reduced from the initial 420 to 282 . Subsequently, due to the dropout of 52 patients during the observation period, 230 patients were finally analyzed (Fig. 1).

In accordance with international guidelines $[9,10]$, all of the patients had been examined and evaluated by ultrasound every 6 months.

Ultrasound assessments were conducted in the morning after fasting for at least $10 \mathrm{~h}$ using Philips HDI 5000 with a 2- to $5-\mathrm{MHz}$ convex probe. Portal vein diameter (PD) was measured as the largest antero-posterior caliber at the crossing point with the hepatic artery during suspended respiration. Diameters below $1.2 \mathrm{~cm}$ were considered normal. No patient had aberrant anatomy of the portal vein.

The longitudinal diameter of the spleen (spleen LD) was evaluated as the maximum bipolar diameter, measurable in the intercostal scan, passing through the splenic hilum. The platelet count/ spleen diameter ratio (PLT/LD) was also calculated [11].
Evaluation of the presence and grade of esophageal varices were performed by endoscopy in $66 \%$ of patients. The treatment history of patients was reviewed for the possible use of $\beta$-blockers. Disease severity was assessed using the Child-Pugh score. Portal vein thrombosis (PVT) onset (suspected on the basis of presence of intraluminal material in the portal vein or one of its branches on ultrasound) was further assessed in all patients by CT and/or MRI imaging.

The use of selective $\beta$-blockers (SBB) was presumed to indicate the presence of comorbidities, in particular cardiovascular disorders. The case study data at 5 years of follow-up was then reviewed; the median follow-up was 3 years ( 6 months to 5 years), with 221 patients at 5 years. In patients treated with $\beta$-blockers the median treatment duration was 24 months.

\section{Statistical Analysis}

Data were expressed as means \pm SD if the distribution was normal, or as medians (range). Differences between means were assessed by Student's $t$ test if the distribution was Gaussian; otherwise, the Mann Whitney U test was used. Fisher's exact test, the $\chi^{2}$ test, odds ratios, and Spearman's rank correlation coefficient were used where appropriate. To identify which variables were significant in univariate analysis for prediction of the onset of PVT, we performed multiple logistic regression analyses where the dependent dicotomic variable was the presence/absence of PVT. These analyses were performed both in the whole population and in patients taking $\beta$-blockers. SPSS Statistics, version 22.0, was used for the statistical analysis. $p<0.05$ was considered statistically significant.

\section{Results}

The baseline clinical, demographic, and biochemical features of our patient series are shown in Table 1. The predominant etiology was $\mathrm{HCV}$, followed by alcoholic and cryptogenic LC. Eighty-eight percent of the patients were in good health and compensation fell within ChildPugh class A. At the esophagogastroduodenoscopy evaluation 149 patients $(64.8 \%)$ showed signs of portal hypertension (esophageal varices) and, among these, $4.3 \%$ had grade $\mathrm{F} 3$ varices. Among the subjects taking $\beta$-blockers, $46.4 \%$ were taking NSBB such as propanolol and carvedilol. During this study 19 patients developed PVT; the prevalence at baseline was $4.5 \%(10 / 230)$, while during follow-up the PVT incidence was $4.3 \%(9 / 211)$ at the 5-year review.

Although the frequency of PVT was higher in ChildPugh B class patients, it did not reach statistical significance; in fact, in Child-Pugh A class patients the frequency of PVT was $6.8 \%(14 / 189)$ versus $18 \%(5 / 22)$ in Child B class patients ( $p=n s$ ), while the presence of F3 varices was significantly more frequent in patients with PVT versus those without PVT (respectively, 19/19 vs. 
Table 2. Demographic and laboratory data at baseline for the 2 patient groups

\begin{tabular}{lcll}
\hline & $\begin{array}{l}\text { No PVT } \\
(n=211)\end{array}$ & $\begin{array}{l}\text { PVT } \\
(n=19)\end{array}$ & $p$ value \\
\hline $\begin{array}{l}\text { Age, years } \\
\text { Male/female ratio }\end{array}$ & $62.4 \pm 10.6$ & $64.6 \pm 12.5$ & $\mathrm{~ns}$ \\
LC etiology & $126 / 85$ & $14 / 5$ & $\mathrm{~ns}$ \\
$\quad$ & & & \\
HCV & $156(73.9)$ & $12(63.1)$ & $\mathrm{ns}$ \\
Alcohol & $8(3.8)$ & $4(21)$ & $\mathrm{ns}$ \\
Metabolic & $6(2.84)$ & $1(5.3)$ & $\mathrm{ns}$ \\
Autoimmune & $5(2.7)$ & 0 & $\mathrm{~ns}$ \\
Cryptogenic & $4(1.9)$ & 0 & $\mathrm{~ns}$ \\
Other & $16(7.6)$ & $2(10.5)$ & $\mathrm{ns}$ \\
& $16(7.6)$ & 0 & $\mathrm{~ns}$ \\
\hline
\end{tabular}

Values are presented as means \pm SD or numbers (\%) unless otherwise stated.

Table 3. Risk factors of PVT in the multiple logistic regression analysis

\begin{tabular}{lcllc}
\hline & $\beta$ & OR & $p$ & $95 \%$ CI \\
\hline PLT count, $n \times 10^{3} / \mathrm{L}$ & 0.000 & 1 & $<0.072$ & $1-1$ \\
$\begin{array}{l}\text { Spleen LD, mm } \\
\text { PLT/LD }\end{array}$ & 0.035 & 1.02 & $<0.11$ & $0.98-1.08$ \\
$\begin{array}{l}\text { Esophageal varices } \\
\text { Esophageal varices }\end{array}$ & 0.05 & 1.0 & $<0.24$ & $0.99-1.04$ \\
$\quad$ & 18.2 & 9 & $<0.89$ & $0.4-25$ \\
$\quad \begin{array}{l}\text { grade 0-1/2/3 } \\
\text { Constes }\end{array}$ & 1.18 & 2.86 & $<0.02$ & $1.31-8.1$ \\
Constant & 1.922 & 6.8 & $<0.11$ & $0.61-76.5$ \\
& -44 & & & \\
\hline
\end{tabular}

Table 4. Risk factors of PVT in the logistic regression analysis in patients treated with $\beta$-blockers

\begin{tabular}{lcclc}
\hline & $\beta$ & OR & $p$ & $95 \%$ CI \\
\hline PLT count, $n \times 10^{3} / \mathrm{L}$ & 0.000 & 1 & $<0.31$ & $1-1$ \\
Spleen LD, mm & 0.044 & 1.02 & $<0.346$ & $0.94-1.1$ \\
PLT/LD ratio & 0.006 & 1.0 & $<0.282$ & $0.98-1.02$ \\
PD, cm & 13.7 & 24.0 & $<0.156$ & $0.7-70$ \\
Esophageal varices & & & & \\
$\quad$ grade 0-1/2/3 & 1.591 & 4.4 & $<0.05$ & $1.2-21.1$ \\
Ascites & 2.421 & 1.1 & $<0.1$ & $0.07-17.5$ \\
NSBB/SBB ratio & 1.2 & 1.12 & $<0.05$ & $1.09-19$ \\
Constant & -13.65 & & & \\
\hline
\end{tabular}

$130 / 211 ; p<0.0001)$. When comparing patients with or without PVT, there was no statistically significant difference in age, gender, or etiology (Table 2), although already at baseline patients with PVT had lower platelet levels $(129,500$ vs. $76,500, p<0.003)$, higher INR values $(1.2 \pm 0.1$ vs $1.1 \pm 0.2, p<0.03)$, a greater spleen diameter (153.0 \pm 20 vs $131 \pm 24.8, p<0.001)$, a lower platelet/ spleen diameter (PLT/DL) ratio (540.7 vs. $996.4, p<$ $0.0005)$ and presence of ascites $(p<0.05)$. Albumin levels were higher in no-PVT subjects, but not significantly (3.96 \pm 0.5 vs. $3.5 \pm 0.96 ; p=n s)$; AST levels were higher in no-PVT patients (i.e., 53 [range 22-288] vs. 43 [range 24-166], $p=n s$ ), while ALT levels were lower in no-PVT patients (i.e., 39 [range 16-113] vs. 59 [range 20-363]; $p=n s$ ), without reaching a statistically significant difference. Bilirubin levels were comparable between no-PVT and PVT patients $(0.94 \pm 0.5$ vs. $0.92 \pm 0.3 ; p=n s)$ and finally the PD was greater in the PVT group but the difference was not statistically significant $(1.25 \pm 0.8$ vs. $1.36 \pm 0.2 ; p=n s$ ). Comparison of patients according to use of $\beta$-blockers treatment showed no significant differences between patients with and without PVT (11/19 vs. $80 / 211 ; p=n s)$. In the multiple logistic regression analysis only the grade of esophageal varices was independently associated with the presence of PVT $(p<0.02)$ (Table 3).

We further analyzed patients taking $\beta$-blockers. In these patients, univariate analysis showed that PVT correlated with grade of esophageal varices $(\rho=0.5 ; p<0.01)$ and that the frequency of PVT in Child-Pugh class B was higher than in Child-Pugh class A patients $(66 \%$ vs. $11.5 \%$; $p<0.02)$. AST levels were higher in PVT patients (i.e., 53 [range $24-163$ ] vs. 52.5 [16-280]; $p<0.03$ ), while ALT levels were higher in no-PVT patients (i.e., 60 [range $22-222$ ] vs. 56 (range 22-218)] and albumin was significantly lower in PVT patients $(4.0 \pm 0.4$ vs. $3.4 \pm 1.1$; $p<$ 0.02 ). In PVT patients both PLT count (i.e., 71,000 [range $42,000-180,000$ ] vs. 93,600 [range $30,000-310,000$ ]) and PLT/LD (i.e., 711 [range 190-1,860] vs. 932 [range 3303,100 ] were significantly lower (both $p<0.03$ ), while spleen LD (133.7 \pm 33.5 vs. $157.0 \pm 35.2 ; p<0.005)$ and $\mathrm{PD}(1.2 \pm 0.14$ vs. $1.4 \pm 0.18 ; p<0.0001)$ were significantly higher; ascites was less frequent in patients without $\operatorname{PVT}(4 / 84$ [9.5\%] and 3/13 [23\%]; $p<0.05)$. There was no statistical difference between the groups with regard to age (which was slightly higher in the PVT group, i.e., 62.6 \pm 10.1 vs. $64.0 \pm 14.4 ; p=n s)$, the male/female ratio $(45 / 39$ for the no-PVT group vs. 10/3 for the PVT group; $p=n s$ ), or bilirubin levels (almost overlapping). In patients with PVT NSSB use was significantly more frequent than in patients with SBB use (11/34 vs. 2/50, OR 8.1; 95\% CI 1.7-38.8). In the multivariate logistic regression analysis, only NSBB and grade of esophageal varices were associated with PVT (Table 4). 


\section{Discussion}

In cirrhotic patients the risk of PVT increases in proportion to the degree of impairment of liver function ranging from a prevalence of $1 \%$ in patients with a good degree of compensation [12] to $8-26 \%$ in decompensated cirrhotic patients awaiting a liver transplant [13]. This trend is understandable because as the cirrhosis progresses the alterations leading to PVT onset become more accentuated. Two fundamental mechanisms in the pathogenesis of PVT in the cirrhotic liver are slowdown of the portal blood flow and the presence of coagulation abnormalities.

The role of coagulation abnormalities has been reconsidered over the years. The old assumption held is that a reduction in the synthesis of coagulation factors by the compromised liver parenchyma would result in a higher hemorrhagic risk, while more recent studies have shown that in LC the situation is actually more complex; reduction of most of the coagulation factors is associated with an increase in factor VIII and Von Willebrand factor and a decrease in protein $\mathrm{C}$, protein $\mathrm{S}$, and antithrombin. In the majority of patients, these alterations are balanced, leading to a sort of precarious homeostasis [14-16].

The slowdown in portal flow is due to an increase in intrahepatic resistance, resulting from subversion of the parenchyma architecture, sinusoid capillarization, and the contractile activity acquired by Ito cells in response to local vasoconstrictors. Flow reduction is further aggravated by the opening of portosystemic collateral circulations which attempt to offer an alternative pathway for the outflow of blood.

These alterations are far less marked in patients with compensated cirrhosis; therefore, if PVT is present it would be appropriate to look for a possible underlying thrombophilic condition. For example, factor V Leiden and prothrombin gene mutations have been shown to be more frequent in cirrhotics with PVT than in those without PVT [17-19]. In LC if the use of NSBB, which cause a further slowdown of the portal flow, is added to the presence of other alterations, this could trigger events leading to PVT. Liver ultrasound surveillance programs in cirrhotic patients should also consider this possible risk factor to identify PVT in its early phase [20].

Our study retrospectively analyzed the medical records of a population of cirrhotic patients in Child-Pugh classes A and B, followed up on an outpatient basis at our center, at 5 years of follow-up. It aimed to assess the prevalence and incidence of PVT and to identify possible risk factors, with particular attention to the use of $\beta$-blockers. Only data regarding compensated LC patients (i.e., Child-Pugh classes A and B) were selected because they were considered representative of our outpatient cohort, while CP class C patients were excluded because there were too few of them to be able to reach statistically significant results; this could be a selection bias in this case study as demonstrated by our results where esophageal varices grade (which is an expression of a more severe disease) is a predictor factor independently associated with the presence of PVT, and this could have led us to underestimate the PVT prevalence and incidence of PVT.

In our case series the prevalence of PVT at baseline $(4.3 \%)$ and its incidence at 5 years were in line with data in the literature $[12,13]$. Since the study population was represented by outpatients, almost all of the patients were still compensated (Child-Pugh class A) and therefore our study was more targeted to identify early risk factors of PVT. As our patients did not come from specialist centers they had often not undergone an endoscopy evaluation, and this may explain the low rate of use of $\beta$-blockers at baseline, whereas its use increased during the follow-up in accordance with treatment guideline indications [21]. However, as not all of the patients had previously given their consent for endoscopy, it was decided to evaluate the presence of portal hypertension in a noninvasive manner using PD and spleen LD values, which are considered the most sensitive US signs of portal hypertension [22], together with the PLT/LD ratio, in order to obtain an indirect indication of the status of portal hypertension at baseline in the majority of patients [11].

At baseline there was a significant correlation between the onset of PVT and spleen size and the grade of varices (both parameters linked to a greater degree of portal hypertension), while the use of $\beta$-blockers was not statistically significant. However, a further analysis of patients taking $\beta$-blockers, divided according to the type of $\beta$-blocker used, revealed that onset of PVT was significantly higher in subjects treated with NSBB. All of these parameters were confirmed as risk factors for PVT on univariate and multivariate analysis.

Recent studies have questioned the efficacy and safety of NSBB in patients with decompensated LC, suggesting the existence of the so-called "window hypothesis," according to which patients with cirrhosis benefit from the use of NSBB in the initial stages when manifestation of portal hypertension first appears (i.e. varices) and up 
to the development of complications. In this later phase, the hemodynamic effects of NSBB may expose patients to the risk of developing further complications such as kidney failure and/or death $[23,24]$.

Our study does not add to the debate on the safety of these drugs in the advanced stages of liver disease, because we analyzed a population of cirrhotic patients with compensated disease. However, it does raise the question of whether compensated patients treated with NSBB should be monitored more closely in order to make an early diagnosis of PVT.

\section{Conclusion}

Even though our results are limited by the fact that this was a retrospective study, it supports the thesis that the development of PVT is favored by a reduction in portal flow, as demonstrated by the correlation between PVT and grade of esophageal varices and spleen diameter. Our data also suggest that, in this pathogenetic framework, the use of NSBB could represent an additional risk factor for PVT even in a phase of compensated cirrhosis (Child-Pugh classes A and B). In light of these preliminary data, prospective studies are necessary to validate our observations.

\section{References}

1 Garcia-Pagàn JC, Buscarini E, Janssen HL, et al: EASL clinical practical guidelines: vascular diseases of the liver. J Hepatol 2016;64:179202.

2 Zocco MA, Di Stasio E, De Cristofaro R, et al: Thrombotic risk factors in patients with liver cirrhosis: correlation with MELD scoring system and portal vein thrombosis development. J Hepatol 2009;51:682-689.

3 Stine JG, Wang J, Shah PM, Argo CK, Intagliata $\mathrm{N}$, Uflacker A, et al: Decreased portal vein velocity is predictive of the development of portal vein thrombosis: a matched casecontrol study. Liver Int 2018;38:94-101.

4 Garcia-Tsao G, Sanyal AJ, Grace ND, et al: Prevention and management of gastroesophageal varices and variceal hemorrhage in cirrhosis. Hepatology 2007;46:922-938.

5 Garcia-Tsao G, Lim JK: Management and treatment of patients with cirrhosis and portal hypertension: recommendations from the Department of Veterans Affairs Hepatitis C Resource Center Program and the National Hepatitis C Program. Am J Gastroenterol 2009;104:1802-1829.

6 de Franchis R: Revising consensus in portal hypertension: report of the Baveno $\mathrm{V}$ consensus workshop on methodology of diagnosis and therapy in portal hypertension. J Hepatol 2010;53:762-768.

7 Qi XS, Bai M, Fan DM: Nonselective $\beta$-blockers may induce development of portal vein thrombosis in cirrhosis. World J Gastroenterol 2014;20:11463-11466.

8 Zampino R, Lebano R, Coppola N, et al: The use of nonselective beta blockers is a risk factor for portal vein thrombosis in cirrhotic patients. Saudi J Gastroenterol 2018;24:25-29.
9 Bruix J, Sherman M, Llovet JM, et al; EASL Panel of Experts on HCC: Clinical management of hepatocellular carcinoma: conclusions of the Barcelona 2000 EASL conference. European Association for the Study of the Liver. J Hepatol 2001;35:421-430.

10 Bruix J, Sherman M; American Association for the Study of Liver Disease: Management of hepatocellular carcinoma: an update. Hepatology 2011;53:1020-1022.

11 Giannini E, Botta F, Borro P, et al: Platelet count/spleen diameter ratio: proposal and validation of a non-invasive parameter to predict the presence of oesophageal varices in patients with liver cirrhosis. Gut 2003;52:12001205.

12 Okuda K, Ohnishi K, Kimura K, et al: Incidence of portal vein thrombosis in liver cirrhosis: an angiographic study in 708 patients. Gastroenterology 1985;89:279-286.

13 Francoz C, Belghiti J, Vilgrain V, et al: Splanchnic vein thrombosis in candidates for liver transplantation: usefulness of screening and anticoagulation. Gut 2005;54:691-697.

14 Tripodi A, Salerno F, Chantarangkul V, et al: Evidence of normal thrombin generation in cirrhosis despite abnormal conventional coagulation tests. Hepatology 2005;41:553-558.

15 Tripodi A, Primignani M, Chantarangkul V, et al: Thrombin generation in patients with cirrhosis: the role of platelets. Hepatology 2006;44:440-445.

16 Monroe DM, Hoffman M: The coagulation cascade in cirrhosis. Clin Liver Dis 2009;13: $1-9$.
17 Amitrano L, Guardascione MA, Brancaccio $\mathrm{V}$, et al: Risk factors and clinical presentation of portal vein thrombosis in patients with liver cirrhosis. J Hepatol 2004;40:736-741.

18 Amitrano L, Brancaccio V, Guardascione $\mathrm{MA}$, et al: Inherited coagulation disorders in cirrhotic patients with portal vein thrombosis. Hepatology 2000;31:345-348.

19 Qi X, Ren W, De Stefano V, et al: Associations of coagulation factor $V$ Leiden and prothrombin G20210A mutations with Budd-Chiari Syndrome and portal vein thrombosis: a systematic review and meta-analysis. Clin Gastroenterol Hepatol 2014;12:1801-1812.e7

20 Puccia F, Lombardo V, Giannitrapani L, et al: Case report: acute portal vein thrombosis associated with acute cytomegalovirus infection in an immunocompetent adult. J Ultrasound 2017;20:161-165.

21 de Franchis R: Evolving consensus in portal hypertension report of the Baveno IV consensus workshop on methodology of diagnosis and therapy in portal hypertension. J Hepatol 2005;43:167-176.

22 Soresi M, Giannitrapani L, Cervello M, et al: Noninvasive tools for the diagnosis of liver cirrhosis. World J Gastroenterol 2014;20: 18131-18150.

23 Sersté T, Melot C, Francoz C, et al: Deleterious effects of beta-blockers on survival in patients with cirrhosis and refractory ascites. Hepatology 2010;52:1017-1022.

24 Reiberger T, Mandorfer M: Beta adrenergic blockade and decompensated cirrhosis. J Hepatol 2017;66:849-859. 